\title{
TO ASSESS KNOWLEDGE \& KNOWLEDGE OF PRACTICE REGARDING STANDARD OPERATING PROTOCOL FOR IMPLEMENTING BEDSIDE HANDOVER IN NURSING AMONG STAFF NURSES AT KRISHNA HOSPITAL, KARAD
}

\author{
Kavita S. Kapurkar1, Rohini Babar², Sandhya Jagadale3, Nitanjali V. Patil4
}

${ }^{1}$ Assistant Nursing Suptd/NABH Co-Ordinator, Krishna Institute of Nursing Sciences Karad, Dist-Satara, Maharashtra.

${ }^{2}$ Nursing Superintendent, Krishna Institute of Nursing Sciences Karad, Dist-Satara, Maharashtra.

${ }^{3}$ Assistant Nursing Suptd/NABH Co-Ordinator, Krishna Institute of Nursing Sciences Karad, Dist-Satara, Maharashtra. ${ }^{4}$ Clinical Instructor, Krishna Institute of Nursing Science Karad, Satara, Maharashtra, India.

\begin{tabular}{l}
\hline ABSTRACT \\
\hline BACKGROUND \\
Bedside handover is based on patient-centred care, where patients participate in communicating relevant and timely information \\
for care planning. Patient input reduces care fragmentation, miscommunication-related adverse events, readmissions, duplication \\
of services and enhances satisfaction and continuity of care. \\
Objectives \\
1. To assess knowledge and knowledge of practice towards standard operating protocol regarding implementing bedside \\
handover in nursing. \\
2. To find an association between knowledge and knowledge of practice with demographic variable.
\end{tabular}

\section{MATERIALS AND METHODS}

The study was conducted on 67 staff nurses at Krishna Hospital, Karad. An evaluatory survey approach was considered. Study design was used descriptive, purposive sampling technique was used. The instrument used for data collection was a questionnaire on knowledge and knowledge of practice.

\section{RESULTS}

Study concludes majority of 44 (66.67\%) staff nurses having average knowledge and 42 (62.68\%) average knowledge of practice of standard protocol in nursing handover \& there was no significant association found between knowledge and knowledge of practice among staff nurses with sociodemographic variables.

\section{CONCLUSION}

Study concludes majority of $44(66.67 \%)$ staff nurses having average knowledge and 42 (62.68\%) average knowledge of practice of standard protocol in nursing handover.

\section{KEYWORDS}

Knowledge, Knowledge of Practice, Standard Operating Protocol for Bedside Handover, Staff Nurse.

HOW TO CITE THIS ARTICLE: Kapurkar KS, Babar R, Jagadale S, et al. To assess knowledge \& knowledge of practice regarding standard operating protocol for implementing bedside handover in nursing among staff nurses at Krishna Hospital, Karad. J. Evolution Med. Dent. Sci. 2016;5(103):7566-7570, DOI: 10.14260/Jemds/2016/1713

\section{BACKGROUND}

Handover is the transfer of professional responsibility and accountability for some or all aspects of care for a patient, or group of patients, to another person or professional group on a temporary or permanent basis.

Communication is central to human interactions. Without it, people cannot relate to those around them, make their needs and concerns known, or make sense of what is happening to them. ${ }^{1}$ Effective communication among nurses is imperative to ensure patient safety and deliver high quality of care. Nursing communication may occur anytime during the shift working hours. However, the communication that

Financial or Other, Competing Interest: None.

Submission 21-11-2016, Peer Review 15-12-2016,

Acceptance 21-12-2016, Published 26-12-2016.

Corresponding Author:

Kavita S. Kapurkar

Krishna Hospital \& Medical Research Centre,

Karad, Dist-Satara,

Maharashtra.

E-mail:kavitakapurkar@gmail.com

DOI: $10.14260 /$ jemds $/ 2016 / 1713$ ncoming nurse (Receiver) is the most common form of communication among nurses, this way of communication is usually called the "End of Shift Report". ${ }^{2}$

Effective communication amongst health professionals is key to ensuring quality care in clinical practice. ${ }^{3}$ One form of communication, clinical handover, has received increasing international attention. Clinical handover has been defined as the transfer of responsibility and/or accountability for patient care from one provider or team of providers to another. ${ }^{4}$ Nursing handover at the bedside has been identified as an important strategy to improve patient-centred care. ${ }^{5}$

Part of most nurses' daily reality is nursing handover. In each hospital, no clear policy for delivering handover and each nurse chose their own method making handover inconsistent. The value placed on handover varied from nurse to nurse and area to area. There are situations which by their very nature give rise to the question and suggest the beginning of an answer. ${ }^{6}$

Nursing has had a long relationship with handover. Handover is a historic, institutionalised ritual that has remained part of nursing culture throughout the decades. Its 
roots lie deep in nursing tradition and nursing handover practice continues without questioning its purpose in contemporary times. Historical traditions such as nursing handover have to be reviewed to highlight the discourse. It is not so much what handover is but more why it exists, why it is maintained and how it affects current healthcare. ${ }^{7}$

Clinical handover has been defined as the process of transferring primary authority and responsibility for providing clinical care to a patient from one departing caregiver to one oncoming caregiver. ${ }^{8}$ Nursing handover or shift report is a type of clinical handover that occurs between two shifts of nurses, whereby the specific purpose is to communicate information about patients under the care of nurses. ${ }^{9}$ Multicentric prospective intervention studies have shown that implementation of hand-off programs are associated with reductions in medical errors and improvements in communication, without a negative effect on workflow. ${ }^{10}$ Some studies have observed a decrease in length of hospital stay and therefore the cost of individual medical visits and fewer referrals. ${ }^{11}$ Though, quality of doctors' handovers is now regarded as a key area for improvement in patient safety. ${ }^{12}$

\section{Need for Study}

The handover is seen as an important part of each nurse's shift. It is a vital method of passing information to nurses on next shift. The nursing handover by Clair and Trussell is the oral communication of pertinent information about patients. Mainly there are four types of handover: recorded, written, verbal (traditional) and bedside. Usually handover traditionally takes place in private, can be lengthy, irrelevant or unprofessional. 13

Communicating nursing care during the patient's total hospital stay is a difficult task to achieve within the context of high patient turn over, a lack of overlap time between shift and time constraints. So, it is better to find alternative for handing over the information. ${ }^{6}$ The best method is bedside handover. It has improved safety, efficiency and team work. Any errors or omissions made during handover process may have dangerous consequences. For example, acute haemolysis caused by transfusion of RBC to wrong patient was one of the major cause for transfusion related deaths which occur due to communication deficiency.

The National Accreditation for Hospitals and Health care providers (NABH) describes that information about patient care and response to treatment is shared among medical and nursing care providers. The information is exchanged and documented during each shift, and during transfer between the units or departments. ${ }^{14}$

The investigator has seen lots of problems due to improper handover. The staff on duty have to call the previous shift staff for clearing doubts or telephoning night duty staff, mostly in the busy morning hours. Because of this, time for patient care is reduced and there is dissatisfaction from patients and relatives. So, the investigator was interested to implement standard nursing handover protocol which can surely reduce the loss of relevant data.

\section{Review of Literature}

The review provides a basis for future investigations, justifies the need for data collection, relates the findings from one study to another with the hope of establishing a comprehensive body of scientific knowledge in a professional manner for which valid and pertinent theories may be developed.

A study was conducted by McFetridge B, Gillespie M, Goode D, Melby V done in UK handover process of initially ill patients by nursing staff from emergency department and ICU. The study used multimethod design that included documentation review, semi-structured interviews to explore the process of patient handover. From 2 acute hospitals, 12 respondents were selected from ED and 3 from ICU from each acute hospital. Qualitative analysis revealed that there was no structured and consistent approach to how handovers actually occurred. Then they recognised the importance of handover in influencing quality of care. 15

O'Connell B, Penney W reported that handover was more than just a forum for communicating patient care. It was necessary to explore more creative ways of conducting the handover of patient care, so that an important aspect of nursing practice does not get classified, as just another ritual. ${ }^{16}$

Meissner A, Hasselhorn HM conducted a study in Germany exploring nurses perceptions of shift handover and reasons for reported dissatisfaction in 10 European countries. The performance and function of shift handover in health care is a widely neglected topic in research and practice. The investigation was done in $2002-2003$ by selfreport questionnaires. They found out that $22 \%$ of nurses were dissatisfied with shift handover in England, 61\% in France. Main reason for dissatisfaction was 'too many disturbances' and 'lack of time'. In several European countries, shift handovers may be a frequent cause for nurses' irritation. The findings have implications for solutions. Further research should clarify the different purposes of handovers. ${ }^{17}$

Jenkin A, Abelson-Mitchell N, Cooper S studied the handover given by ambulance staff. For this study, 4 emergency departments and one ambulance service were included. A descriptive, non-experimental cross-sectional survey method was used. A questionnaire was distributed to a convenience sample of ambulance paramedics and emergency nurses. The results showed emergency department staff needed to appreciate that a lack of active listening skills could lead to frustration for ambulance staff. Ambulance staff must expect to repeat their handover, especially for patients in the resuscitation room. Suggestions were made for improving handover by developing national guidelines and by incorporating handover in emergency department education. ${ }^{18}$

Currie J, conducted an audit in orthopaedic and surgical ward to find out the suitable handover method, and time spent on handover. The researcher audited ten handovers, five from each ward with the use of audit checklist. The audit that $60 \%$ of the sample group used the nursing documentation as part of handover, $70 \%$ included past medical history in their handover and only $20 \%$ of the handover carried out in patient's room. The length of the handover was appropriate for the number of patients. The audit concluded the need for patient involvement and should be carried out using relevant information from up-to-date period. 19 
Parmeshwar Kumar, V Jithesh, AartiVij, Shakti Kumar Gupta was conducted descriptive and cross-sectional study over 4 months in a 200-bedded public sector tertiary care facility in New Delhi, India. Three hundred and eighty two handovers each of nurses and doctors revealed varying adherence for time (44\%), place (63\%), documentation $(50 \%)$, process $(78 \%)$, staff interaction $(50 \%)$ and patient communication $(45 \%)$ related elements with overall compliance being $55 \%$. Doctors fared better only in process elements and bedside handovers; however, only nurses had a statistically significant fall in levels over weekends and in night shifts. Staff interaction and patient communication were positively correlated and bedside handover was negatively related to handover duration in both groups. No statistically significant difference was found between the two groups when assessed as categories. ${ }^{20}$

A study was conducted by Voyer P.Cole MG, MC Custer J, St-Jacques S, Laplante $J$ to evaluate the sensitivity and specificity of documentation of nurse reported delirium symptoms in medical charts. The study was based on clinical assessments of nursing notes of 225 delirious older patients. The results indicated that documentation of delirium symptoms was poor. The documentation of delirium according to nursing process of care was, out of 225 patients only 145 patients who have at least 1 symptom documented, 54 patients with confusion documented. 21

A study conducted by Joanne M Fitzpatrick, Alison While and Julia D Roberts on Shift work and its impact upon nurse performance - current knowledge and research issues at King's College, London on 34 staff nurses results shows that all staff nurses were within the first year of practice. In our study, 54 (36.18\%) staff nurses' experience was in between $1-3$ years. ${ }^{22}$

\section{MATERIALS AND METHODS}

The study was conducted on 67 staff nurses at Krishna Hospital, Karad. An evaluatory survey approach was considered. Study design used - descriptive, purposive sampling technique was used. The instrument used for data collection was a questionnaire of knowledge and knowledge of practice.

\section{Inclusion Criteria for Sampling}

- Registered staff nurses who are willing to participate in the study.

- The morning and evening handover sessions.

- The handover of patients who are newly admitted on that particular day.

\section{Exclusion criteria}

- Staff nurses who are not willing to participate in the study.

- The handover of patients who are admitted in the ward before the study.

- The handover sessions at night shift.

\section{Instrument Used}

Standard Handover Protocol as follows:

\section{Protocol}

It is a standard format for data representation, error detections used for transmission of information. In this study, it refers to a standard checklist that enables the transmission of patient information between the shift changes of nursing staff.
The Handover Protocol will include the given Criteria

- Reason for admission.

- Past medical history.

- Abnormal lab results.

- Recent investigations.

- Sudden changes in the condition.

- Medications.

- Intake output.

- Reference to nursing documentation.

\section{Assumptions}

- The handover of patient information takes place during the nurses' shift change in different ways.

- The routine handover takes place with using a protocol.

\section{Delimitations}

- This study is limited to one month.

- This study is limited to Krishna Hospital.

- Hypothesis. (The hypothesis will be tested at 0.05 level of significance.)

- $\mathrm{H}_{1}$ : There will be significant difference in the effectiveness of bedside handover with the use of protocol.

\section{RESULTS}

Analysis and interpretation of the data was based on the projected objectives of the study viz.

1. To assess knowledge and knowledge of practice towards standard operating protocol regarding implementing bedside handover in nursing.

2. To find an association between knowledge and knowledge of practice with demographic variable.

\begin{tabular}{|c|c|c|}
\hline $\begin{array}{l}\text { Sl. } \\
\text { No. }\end{array}$ & Variables & Frequency (\%) \\
\hline \multirow{5}{*}{1} & Age & \\
\hline & 21 - 23 yrs. & $20(29.85)$ \\
\hline & 24 - 26 yrs. & $30(44.77)$ \\
\hline & 27 - 30 yrs. & 08(11.94) \\
\hline & $>31$ yrs. & $09(13.43)$ \\
\hline \multirow{3}{*}{2} & Gender & \\
\hline & Male & $15(22.38)$ \\
\hline & Female & $52(77.61)$ \\
\hline \multirow{4}{*}{3} & Education & \\
\hline & $\begin{array}{c}\text { RGNM(Registered General Nurse \& } \\
\text { Midwife) }\end{array}$ & $40(59.70)$ \\
\hline & B. BSc & $20(29.85)$ \\
\hline & PB B.Sc & $07(10.44)$ \\
\hline \multirow{4}{*}{4} & Experience & \\
\hline & 1 - 3 yrs. & 54 (80.59) \\
\hline & 4 - 6 yrs. & $05(7.46)$ \\
\hline & $>7$ yrs. & $08(11.94)$ \\
\hline
\end{tabular}

Table No 1. Reveals that majority of staff nurses 30 (44.77\%) belong to age group of 24-26 years. Maximum staff $52(77.61 \%)$ were female, majority $40(59.77 \%)$ staff were educated RGNM. Maximum staff 54 (80.59\%) job experience was 1-3 years. 


\begin{tabular}{|c|c|c|c|c|}
\hline $\begin{array}{c}\text { Sl. } \\
\text { No. }\end{array}$ & Particular & Frequency \% & Mean/SD & P. value \\
\hline 1 & Good & $17(25.37)$ & \multirow{3}{*}{$42.59 / 4.25$} & \multirow{2}{*}{$<0.0001$} \\
\hline 2 & Average & $28(41.79)$ & & \\
\hline 3 & Poor & $22(32.83)$ & & \\
\cline { 1 - 3 } & & &
\end{tabular}

Table 2. Categorisation According to Knowledge and

Knowledge of Practice Score among Staff Nurses. $N=67$
Table No.2 indicates that majority of 28 (41.79\%) staff nurses are having average knowledge and knowledge of practice of standard protocol in nursing Handover.

\begin{tabular}{|c|c|c|c|c|c|c|c|c|}
\hline Assessment & Good & Average & Poor & Mean & SD & P Value & Unpaired t Test & df \\
\hline Knowledge & $\begin{array}{c}8 \\
(11.94)\end{array}$ & $\begin{array}{c}44 \\
(66.67)\end{array}$ & $\begin{array}{c}15 \\
(22.38)\end{array}$ & 19.77 & 2.124 & \multirow{2}{*}{$<0.0001$} & \multirow{2}{*}{6.985} & \multirow{2}{*}{132} \\
\hline Practice & $\begin{array}{c}18 \\
(26.86)\end{array}$ & $\begin{array}{c}42 \\
(62.68)\end{array}$ & $\begin{array}{c}7 \\
(10.44)\end{array}$ & 22.80 & 2.846 & & & \\
\hline
\end{tabular}

Table No.3 indicates that majority of $44(66.67 \%)$ staff nurses are having average knowledge and 42 (62.68\%) average knowledge of practice of standard protocol in nursing Handover.

\begin{tabular}{|c|c|c|c|c|c|c|c|c|}
\hline Sl. No. & Variables & Particulars & Good & Average & Poor & $\begin{array}{c}\text { Chi } \\
\text { Square } \\
\text { Value }\end{array}$ & p.value & df \\
\hline 1 & Age & 21-25 years & 7 & 26 & 14 & \multirow{2}{*}{3.914} & \multirow{2}{*}{0.1413} & \multirow{2}{*}{2} \\
\hline & & $>26$ years & 2 & 16 & 2 & & & \\
\hline 2 & Gender & Male & 4 & 9 & 5 & \multirow{2}{*}{2.204} & \multirow{2}{*}{0.3322} & \multirow{2}{*}{2} \\
\hline & & Female & 5 & 33 & 11 & & & \\
\hline 3 & Education & RGNM & 6 & 26 & 9 & \multirow{3}{*}{0.7397} & \multirow{3}{*}{0.9463} & \multirow{3}{*}{4} \\
\hline & & B. BSc & 2 & 13 & 5 & & & \\
\hline & & PB BSc & 1 & 3 & 2 & & & \\
\hline 4 & Experience & $1-3$ years & 6 & 33 & 15 & \multirow{3}{*}{2.997} & \multirow{3}{*}{0.2235} & \multirow{3}{*}{2} \\
\hline & & 4-6 years & 1 & 2 & 1 & & & \\
\hline & & $>7$ years & 2 & 7 & 0 & & & \\
\hline
\end{tabular}

Table No.4 indicates there was no significant association found between knowledge of staff nurses with sociodemographic variables.

\begin{tabular}{|c|c|c|c|c|c|c|c|c|}
\hline Sl. No. & Variables & Particulars & Good & Average & Poor & $\begin{array}{c}\text { Chi } \\
\text { Square } \\
\text { Value }\end{array}$ & p.value & df \\
\hline \multirow[t]{2}{*}{1} & Age & $21-25$ years & 11 & 33 & 5 & \multirow{2}{*}{1.927} & \multirow{2}{*}{0.3815} & \multirow{2}{*}{2} \\
\hline & & $>26$ years & 7 & 10 & 1 & & & \\
\hline \multirow[t]{2}{*}{2} & Gender & Male & 4 & 10 & 2 & \multirow{2}{*}{2.481} & \multirow{2}{*}{0.2892} & \multirow{2}{*}{2} \\
\hline & & Female & 14 & 33 & 4 & & & \\
\hline \multirow[t]{3}{*}{3} & Education* & RGNM & 12 & 24 & 5 & \multirow{3}{*}{1.990} & \multirow{3}{*}{0.3698} & \multirow{3}{*}{2} \\
\hline & & B.BSc & 4 & 15 & 1 & & & \\
\hline & & PB BSc & 2 & 4 & 0 & & & \\
\hline \multirow[t]{3}{*}{4} & Experience\# & 1-3 years & 12 & 37 & 5 & \multirow{3}{*}{3.079} & \multirow{3}{*}{0.2145} & \multirow{3}{*}{2} \\
\hline & & 4-6 years & 1 & 3 & 0 & & & \\
\hline & & $>7$ years & 5 & 3 & 1 & & & \\
\hline
\end{tabular}

Table No 5. indicates there was no significant association found between knowledge of practice among staff nurses and sociodemographic variables.

\section{Key}

*: Indicates that Education, B.BSc, PB BSc has complied in to Graduate for analysis purpose.

\#: Indicates 4-6 years and $>7$ years complied in to $>4$ years for analysis purpose.

\section{DISCUSSION}

Contradictory findings seen in study conducted by Joanne M Fitzpatrick, Alison While and Julia D Roberts on Shift work and its impact upon nurse performance - current knowledge and research issues at King's College, London on 34 staff nurses results show that all staff nurses were within the first year of practice, in our study 54 (36.18\%) staff nurses experience was in between 1-3 years. 


\section{CONCLUSION}

Study concludes majority of $44(66.67 \%)$ staff nurses were having average knowledge and 42 (62.68\%) were having average knowledge of practice of standard protocol in nursing handover. There was no significant association found between knowledge and knowledge of practice among staff nurses with sociodemographic variables.

\section{FUTURE SCOPE}

\section{Nursing Implication}

The findings of this study have implications for nursing practice, nursing education, nursing administration and nursing research.

\section{Nursing Practice}

The knowledge and knowledge of practice of standard operating protocol for implementing bedside handover in nursing needs to be provided to all nursing personnel and can be continued in the hospital.

\section{Nursing Administration}

The finding of the study will help the nurse administrator to organise more workshops, panel discussion, short-term refresher courses and health education programme for nurses.

\section{Nursing Research}

Researchers suggest that standard operating protocol is a good way to avoid duplication of services, it enhances satisfaction and continuity of care.

\section{REFERENCES}

[1] Chairman. National association of clinical tutors. Safe handover safe patients. National patient safety agency, British medical association: London.

[2] Casey A, Wallis A. Effective communication: principle of nursing practice E. Nurs Stand 2011;25(32):35-7.

[3] Nadzam DM. Nurses' role in communication and patient safety. Journal of Nursing Care Quality 2009;24(3):1848.

[4] World Health Organization. Communication during patient hand-overs. Patient safety solutions 2009.

[5] Chaboyer W, McMurray A, Johnson J, et al. Bedside handover quality improvement strategy to transform care at the bedside. Journal of Nursing Care Quality 2009;24(2):136-42.

[6] Morrison M. Safe handover safe patients guidelines on clinical handover for clinicians and managers. Australian Resource Centre for Healthcare Innovations 2006.
[7] Merleau-Ponty J, Morando B. The rebirth of cosmology. New York NY Knopf Inc 2006.

[8] Cheek J. Postmodern and poststructural approaches to nursing research. Thousand Oaks, CA: Sage 2000.

[9] Australian commission on safety and quality in health care-clinical handover. ACSQHC 2012.

[10] Lamond D. The information content of the nurse change of shift report: a comparative study. J Adv Nurs 2000;31(4):794-804.

[11] Root causes of sentinel events. all categories Oakbrook. IL Joint Commission: 2006. http://www.jointcommission.org/NR/rdonlyres/FA46 AF E8AF6571E372/0/root_cause_se.jpg.

[12] Whale Z. The participation of hospital nurses in the multidisciplinary ward round on a cancer-therapy ward. J Clin Nurs 2004;2(3):155-63.

[13] Chio A, Montuschi A, Cammarosano S, et al. ALS patients and caregivers communication preferences and information seeking behaviour. Eur J Neurol 2008;15(1):55-60.

[14] National accreditation board for hospitals and healthcare providers. $2^{\text {nd }}$ edn. NABH standards for hospitals. Access assessment and continuity of care 1, No:13 2007.

[15] McFetridge B, Gillespie M, Goode D, et al. An exploration of handover process critically ill patients between nursing staff from the emergency departments and the intensive care unit. Nursing critical 2007;12(6):261-9.

[16] O'Connell B, Penney W. Challenging the handover ritual. Recommendations for research and practice. Collegian 2001;8(3):14-8.

[17] Jenkin A, Abelson-Mitchell N, Cooper S. Patient handover: time for a change? Accident Emergency Nursing 2007;15(3):141-7.

[18] Meissner A, Hasselhorn HM, Estryn-Behar M, et al. Nurses perception of shift handovers in Europe: results from the European nurses early exit study. Journal of Advanced Nursing 2007;57(5):535-42.

[19] Currie J. Audit of nursing handover. Nursing times 2000;96(42):44.

[20] Kumar P, Jithesh V, Aartivij, et al. Comparative study of clinical handovers among doctors and nurses in a tertiary care center in India. International Journal of Research Foundation 2015;3(1):33-40.

[21] Voyer P, Cole MG, McCuster J, et al. Accuracy of nurse documentation of delirium symptoms in medical charts. International journal of Nursing 2008;14(2):165-77.

[22] Fitzpatrick JM, While A, Roberts JD. Shift work and its impact upon nurse performance: current knowledge and research issues. Journal of Advanced Nursing 1999;29(1):18-27. 